\title{
CHALLENGES OF CLASSIFICATION OF STAND-ALONE SOFTWARE AS A MEDICAL DEVICE
}

D0l:10.36740/WLek202102129

\author{
Vitalii M. Pashkov ${ }^{1,2}$, Oleksii S. Soloviov ${ }^{3}$, Yevheniia 0. Harkusha ${ }^{1,2}$ \\ 'POLTAVA LAW INSTITUTE OF YAROSLAV MUDRYI NATIONAL LAW UNIVERSITY, UKRAINE, POLTAVA, UKRAINE \\ ¿LABORATORY FOR THE STUDY OF NATIONAL SECURITY PROBLEMS IN THE FIELD OF PUBLIC HEALTH OF ACADEMICIAN STASHIS SCIENTIFIC RESEARCH \\ INSTITUTE FOR THE STUDY OF CRIME PROBLEMS, POLTAVA, UKRAINE \\ ${ }^{3}$ NATIONAL SECURITY AND DEFENSE COUNCIL OF UKRAINE, KYIV, UKRAINE
}

\begin{abstract}
Through a broad literature review, analysis of EU, USA, Ukraine regulation acts, scientific research, and opinions of progressive-minded people in this sphere, this paper provides a guide to understanding the essence of classification of stand-alone software with medical purpose and specifics of its regulation. This research is based on dialectical, comparative, analytic, synthetic, and comprehensive methods.
\end{abstract}

KEY WORDS: apps, applications, software, medical devices, classification, medical devices directive, medical devices regulation, legislation, classification, authorized body

Wiad Lek. 2021;74(2):327-333

\section{INTRODUCTION}

Thousands of applications, algorithms, and pieces of software have been developed in the healthcare field over the past few years, all with the aim of improving patient health and assisting doctors in clinical decisions. Apps and computer programs are designed to do everything from track menstrual periods to help anesthesiologists during surgery. In many cases, they have also been proposed to help guide decision-making when tumors should be biopsied or when medication should be delivered [1].

As the number of products has increased, the authorities in different countries work hard to develop and implement relevant legislation and guidelines. Furthermore, one of the most challenging matters in this regard is stand-alone software classification, and it will be the focus of this particular research.

\section{MATERIALS AND METHODS}

Through a broad literature review, analysis of EU, USA, Ukraine regulation acts, scientific research, and opinions of progressive-minded people in this sphere, this paper provides a guide to understanding the essence of classification of stand-alone software with medical purpose and specifics of its regulation. This research is based on dialectical, comparative, analytic, synthetic, and comprehensive methods.

\section{REVIEW AND DISCUSSION}

I. Stand-alone software classification rules: EU, USA, and Ukrainian approaches

The first question that has to be answered by the manufacturer of stand-alone software in the health sphere - is this software a medical device or not? This question got significant scientific attention and was partly covered in our previous researches [2-9]. That is why we will move further, leaving these basic points.

Once a stand-alone software is qualified as a medical device, the next question to be answered is into what classification group it should fall.

In the European Union (hereinafter - EU), the documents that regulate this question are Medical Device Directives (MDD): AIMDD 90/385/EEC; MDD 93/42/EEC; IVDMDD 98/79/EC (hereinafter - MDD). The MDD defines possible classes for medical devices as being either Class I, IIa, IIb, or III and provides a set of rules for deciding on the appropriate classification for a device. These rules, called "implementing rules", are contained in Annex IX of the MDD [10].

Section 1.4 of Annex IX states clearly that 'stand-alone software is considered to be an active medical device':

"Any medical device operation of which depends on a source of electrical energy or any source of power other than that directly generated by the human body or gravity and which acts by converting this energy. Medical devices intended to transmit energy, substances, or other elements between an active medical device and the patient, without any significant change, are not considered to be active medical devices. The stand-alone software is considered to be an active medical device". [10]

This means that implementing rules $9,10,11$, and 12 may apply, depending on the stand-alone software's function and purpose.

The new Medical Device Regulation, published in April 2017 and replacing the MDD in May 2020, puts more emphasis on software [11]. 
General-purpose software or software for life-style and well-being purposes is explicitly excluded from the MDR. Compared to the MDD, there is an additional classification rule (rule 11) for software in the MDR that covers other types of software.

Thus, Rule 11 states that software intended to provide information which is used to make decisions with diagnosis or therapeutic purposes is classified as class IIa, except if such decisions have an impact that may cause:

death or an irreversible deterioration of a person's state of health, in which case it is in class III; or

a serious deterioration of a person's state of health or surgical intervention, in which case it is classified as class IIb.

Software intended to monitor physiological processes is classified as class IIa, except if it is intended for monitoring of vital physiological parameters, where the nature of variations of those parameters is such that it could result in immediate danger to the patient, in which case it is classified as class IIb.

All other software is classified as class I [11].

It is important to say that under the MDD, the majority of software falls under Class I, the more stringent MDR requirements may determine the reclassification of some mHealth Apps into a higher risk class. Examples of up-classification from Class I to Class IIa are an app that measures reaction time to help diagnose a concussion and an app that calculates the risk of having a heart attack in the next ten years based on cholesterol levels. An example of up-classification from Class I to Class IIb is an app that provides information on the required dose of medicine (an anticoagulant) based on the measurement of the international normalized ratio (INR) value for blood clotting. In this case, it was assumed that the app calculates this value using an algorithm. One app was classified as Class I under the MDD but will be a Class III medical device under the MDR. This is an app predicting the three-month mortality risk in patients with chronic liver disease. This score is used for prioritization of donor organ allocation to patients awaiting liver transplantation [12, p.19].

Moving from Class I to a higher class implies notified body involvement in the conformity assessment, which represents a heavier burden for mHealth Apps developers in terms of budget and time planning [13].

In the USA, as in the EU, medical devices software could fall under all types of classes. Thus, The Policy for Device Software Functions and Mobile Medical Applications, issued by the FDA, defines that for device software functions, manufacturers must meet the applicable device classification requirements. Thus, If the device, on its own, falls within a medical device classification, its manufacturer is subject to the requirements associated with that classification. A device software function, like other devices, may be classified as class I (general controls), class II (special controls in addition to general controls), or class III (premarket approval) [14, p. 10].

For comparison, Ukrainian legislation defines four classes for medical devices: I, IIa, IIb, and III (paragraph 14 of the Technical Regulations, medical devices) [15]. Classi- fication is carried out per the criteria set out in Annex 2. Paragraph 5 of Annex 2 of the Technical Regulation, which stipulates that software that controls a medical device's operation or affects a medical device's use belongs to the same class as this medical device [15]. It follows that software that is part of another medical device has the same class as this medical device. In fact, with this category of software, everything is obvious, and no questions arise. In our opinion, it is much more challenging to classify software that is available to the user as a separate medical device and is not a part of any other "hardware" medical device. In order to determine the class of this type of software, we refer to the general rules of classification of non-invasive (those that do not come into contact with the patient or come into contact only with intact skin) medical devices provided for in paragraphs 9-12 of Annex 2 above. All non-invasive medical devices are in Class I unless the provisions of this section apply [15]. An analysis of the provisions of this section shows that its provisions do not apply to the software. Therefore, stand-alone software belongs to class I (the lowest degree of risk).

It should be noted that in the methodological recommendations on the application of the Technical Regulation on medical devices approved by the Order of the Ministry of Health of Ukraine dated 22.01.2020 № 142, which provide additional clarifications, including the classification of medical devices, no guidelines or ancillary tools that would help with the classification of stand-alone software are not contained [16]. Only in the document Methodical Recommendations "Medical devices. Aids. Producer." [16] explains whether a product, in particular software, can be considered to have a medical purpose (namely, for this purpose, the software belongs to the category of medical devices) or not. Thus, these recommendations clearly state that the product's medical purpose is absent when the software is used to process general patient data [16]. However, this rule in no way affects the fact that individual software belongs to class I.

Summarizing the abovementioned, we can conclude that the Ukrainian approach in stand-alone software classification is not aligned with EU and USA approaches, when stand-alone software could fall under all types of medical device's classes depending on the level of the risk, where the premarket way of stand-alone software can include involving a notified body and grant their effectiveness and safety for potential customers.

\section{Certified in EU and USA stand-alone software: classification and learnings}

We have analyzed the directory of certified apps in the EU and USA [17], which includes 213 medical devices from the different standpoints, including classification, summarized results are below (Table 1, Table 2).

As we can see from the table above, the most popular categories of certified stand-alone software are Heart/ Circulatory System, Diabetes, Patient monitoring, and Respiratory system.

In this regard, it is also interesting to compare the number of certified stand-alone software as a medical device 
Table 1. Medical area for use

\begin{tabular}{|c|c|c|}
\hline Category & № & $\%$ \\
\hline Heart/Circulatory System & 41 & 19,25 \\
\hline Diabetes & 36 & 16,9 \\
\hline Patient monitoring & 29 & 13,62 \\
\hline Respiratory system & 21 & 9,86 \\
\hline Eyes and Ears & 11 & 5,16 \\
\hline Mental Health and Behavioral Disorders & 11 & 5,16 \\
\hline Genitourinary system & 8 & 3,76 \\
\hline Communication System & 8 & 3,76 \\
\hline Pain management & 6 & 2,82 \\
\hline Sleep management & 5 & 2,35 \\
\hline Musculoskeletal system and connective Tissue & 5 & 2,35 \\
\hline Oncology & 5 & 2,35 \\
\hline Fertility & 2 & 0,94 \\
\hline Epilepsy & 2 & 0,94 \\
\hline Real-time monitoring of tissue oxygen & 1 & 0,47 \\
\hline Infant feeding & 1 & 0,47 \\
\hline Drug delivery & 1 & 0,47 \\
\hline Chronic disease management & 1 & 0,47 \\
\hline Skin and subcutaneous tissue & 1 & 0,47 \\
\hline Medical devices with a few purposes and others & 18 & 8,45 \\
\hline
\end{tabular}

according to the conformity assessment rules and the total number of medical and health software available in the relevant categories in online stores. Thus, as we mentioned above, according to the information provided in our analyzed database, there is 213 certified software that has a medical purpose. In the Google Play store, in section "Applications," category "Medicine," in the list of TOP free applications, there are 200 units, in section bestsellers - 54 units; TOP paid - 188 units. Also, there is a separate category - "Health and Fitness," which offers various fitness programs, pedometers, and fitness trackers, which do not qualify as medical devices [18]. The AppStore also includes several categories of software that can be used for medical purposes: "Health and Fitness," where 234 programs are offered as popular at once; "Medicine" - 240 programs stand out as popular [19]. The Microsoft Store, in turn, also has both categories: "Medicine" - 204 programs and "Health and Fitness" - 739 programs are available [20].

This indicates that the number of stand-alone software that may have a medical purpose, and therefore is required to undergo a proper conformity assessment procedure on the market much more than duly registered and provided in the analyzed database of certified apps. As a result, it is likely that some medical software may pose a risk to human life and health and is a medical device but has not been adequately tested before it is made available to the end-user.

Within the framework of this classification criterion, it is possible to note that the market is not as defined as other goods in the field of software trade because it is sold via the
Internet. Moreover, although the stand-alone software in the above pages is distributed by location, i.e., the user is displayed for sale software available at his location. However, this does not preclude the use of VPN technology to hide the location and access the software from "another market".

Besides, a sample analysis of 30 programs from the "Medicine" section of GooglePlay, available to Ukrainian users, showed that none of the programs contains a national mark of conformity that should be applied if such software is classified as a medical device and has passed the conformity assessment [21]. Which in turn, can mean one of two things: either all the software under analysis is not a medical device in the sense of national law, or some of the software is a medical device but has not passed the proper conformity assessment procedure according to the Technical Regulations for Medical Devices.

From this classification, it can be concluded that the vast majority (about $71 \%$ ) of certified stand-alone software is represented in both the AppStore and Google Play, indicating that there are sufficient staff to develop and maintain multi-platform software (at least for Android and iOS operating systems), which can usually be afforded by medium and large companies that already have a success story on one of the platforms. From these statistics, it can be indirectly concluded that small companies and start-ups cannot afford to go through the conformity assessment procedure (Table 3 ).

From the analysis, it can be concluded that the vast majority (105 against 20) of medical software, which is 
Table 2. Sales market

\begin{tabular}{ccc}
\hline Market & № & \% \\
\hline Only USA & 81 & 38,74 \\
\hline Only EU & 45 & 21,53 \\
\hline Both EU and USA & 83 & 39,73 \\
\hline
\end{tabular}

Table 3. The way of distribution

\begin{tabular}{ccc}
\hline The way of distribution & № & \% \\
\hline AppStore, Google Play and website & 149 & 71,59 \\
\hline AppStore and Website & 36 & 17,3 \\
\hline Google Play and Website & 13 & 6,24 \\
\hline Only Website & 10 & 4,87 \\
\hline
\end{tabular}

Table 4. The class of certified stand-alone software EU

\begin{tabular}{cccc}
\hline Class & № & \% \\
\hline CE I & 105 & 84 \\
\hline CE II a & 15 & 12 & 4 \\
\hline CE II b & 5 & 4 \\
\hline
\end{tabular}

Table 5. The class of certified stand-alone software USA

\begin{tabular}{ccc}
\hline Class & № & \% \\
\hline FDA 510 $(\mathrm{k})$ & 135 & 88,24 \\
\hline FDA 510 $(\mathrm{k})$ exempt & 4 & 2,61 \\
\hline FDA class I & 6 & 3,92 \\
\hline FDA class II & 8 & 5,23 \\
\hline
\end{tabular}

designed for the EU market, is classified according to CE I class, which has the lowest degree of risk to humans and provides the most painless procedure for conformity assessment, namely self-assessment and completion declaration, therefore, does not require the involvement of a conformity assessment body (Table 4 ). The situation is similar to medical software available to users in the US (Table 5). Thus, the vast majority of such software (105) entered the market after submitting form $510(\mathrm{k})$. In fact, in this form, the medical software manufacturer must demonstrate that its medical device is as safe and effective as a similar medical device (medical software) that already legally exists on the market [22].

III. Stand-alone software classification: practical issues

Previously we considered what classes of medical devices could be applied for stand-alone software in the EU, USA and Ukraine, analyzed the database of certified stand-alone software in the EU and USA, and now we would like to explore how classification rules work in practice on the example of one stand-alone type software in the category Birth control.

From the database of certified health apps [17], we can see just one software that the FDA cleared in the US and CE-marked in Europe as a medical device - Natural Cycles - Birth Control App [23]. The main functions of this app are 1) Knowledge of when a woman is fertile and when is not; 2) Reliable ovulation detection and predictions; 3) Personal insights around your cycle, enabled by our proprietary algorithm; 4) Useful notifications, including PMS alerts and when your period is due. Natural Cycles was classified as a medical device that falls under Class II a.

Let's see what recommendations regarding classification was provided in the Manual on borderline and classification in the community regulatory framework for medical devices Version 1.22 (05-2019) (Table 6). Even though this document is not legally binding, it was developed by the group that was chaired by the commission and composed of representatives of all member states of the EU, EFTA, and other stakeholders [24]. This Manual provided three examples of the classification of birth control apps.

As we can see, the first, second, and third apps are working in the same way, but the first one is classified as Class I and the second, and the third as Class IIb. The difference is in intended purpose: just facilitate conception or facilitate conception and prevent pregnancy. If the manufacturer declares the purpose of preventing pregnancy - it has to be Class IIb.

Returning to Natural Cycles, this app was classified as Class IIa, and its intended purpose - Birth Control (in this case, it is unclear if it was designed just to facilitate conception or prevent pregnancy as well). Thus, under these four examples, we can see that four apps with the same functions and that can be used for the same purpose could be classified as Class I, Class IIa, or Class IIb depending on the manufacturer's purpose. The only common feature - all of them are qualified as a medical device. Consider- 
Table 6. Examples of the classification of birth control apps [24].

Category: Product intended to facilitate conception based on basal body temperature

Description: The product in question measures the basal body temperature (BBT) orally, records it and uses the daily BBT and menstruation days to track the menstrual cycle and predict ovulation. Once it has enough data from the user, it calculates the user's fertility status based on a validated statistical algorithm as claimed by the manufacturer. The fertility status of the current day is reflected by one of three indicator lights: red (fertile), green (infertile) or yellow (learning phase/cycle fluctuation).The temperature sensor, the activation button (interface), the processor (storing of data and fertility status calculator) and the menstruation and fertility status indicators are all integrated into a single piece of equipment. The product is battery-driven. It does not display the user's

temperature and is not intended to allow direct diagnosis or monitoring of vital physiological processes, i.e., it is not intended to be used as an electronic thermometer. It is claimed by the manufacturer to facilitate conception by predicting ovulation.

Outcome: The product is intended by the manufacturer to facilitate conception and should be qualified as a medical device. According to clauses 1.2 and 1.4 of chapter I, Annex IX MDD, this device is considered to be an invasive active medical device and should be classified as class I according to rule 12

Category: Product intended to facilitate conception and enable contraception based on basal body temperature Description: The product in question measures the basal body temperature (BBT) orally, records it and uses the daily BBT and menstruation days to track the menstrual cycle and predict ovulation. Once it has enough data from the user, it calculates the user's fertility status based on a validated statistical algorithm as claimed by the manufacturer. The fertility status of the current day is reflected by one of the three indicator lights: red (fertile),

green (infertile) or yellow (learning phase/cycle fluctuation).The temperature sensor, the activation button

(interface), the processor (storing of data and fertility status calculator) and the menstruation and fertility status indicators are all integrated into a single piece of equipment. The product is battery-driven. It does not display the user's temperature and is not intended to allow direct diagnosis or monitoring of vital physiological processes, i.e., it is not intended to be used as an electronic thermometer. The product in question is claimed by the manufacturer to facilitate conception and prevent pregnancy.

Outcome: The product is intended by the manufacturer to (i) facilitate conception or (ii) prevent pregnancy, and should therefore be qualified as a medical device. According to clause 4.2 of chapter III, Annex IX MDD, all devices used for contraception or the prevention of the transmission of sexually transmitted diseases are in Class IIb (rule 14). The explanations of rule 14 in the MEDDEV 2.4/1 Rev. 9 emphasize that "the intended uses relate to special cases of human vulnerability that cannot be covered by the normal criteria of time, invasiveness and organic function." Unwanted pregnancy is a case of human vulnerability. According to clauses 1.2 and 1.4 of chapter I, clause 2.5 of chapter II and clause 4.2 of chapter III, Annex IX MDD, and in consideration of the above-mentioned rationale, this device is considered to be an invasive active medical device and should be classified as class llb according to rule 14 .

Category: Standalone software application for conception and contraception purposes using data entered by the patient

Description: The product in question is claimed by its manufacturer to be a natural method of birth control. It is a standalone software application that combines the calendar/rhythm method, the body basal temperature (BBT)

method and the cervical mucus method to both (i) prevent pregnancy and (ii) target the most fertile time for getting pregnant. The user enters her data (first day of menstruation, BBT measured with a common thermometer and consistency of the cervical mucus) and obtains the fertility window.

Outcome: The product is intended by the manufacturer to (i) prevent pregnancy or (ii) facilitate conception, and should be qualified as a medical device. According to clause 1.4 of chapter I, clause 2.5 of chapter II and clause 4.2 of chapter III, Annex IX MDD, this standalone software is considered to be an active medical device and should be classified as class IIb according to rule 14.

ing those mentioned above, the more strange the market situation looks, thus just in Google Play, there are more than 250 woman's apps [25] with similar functions and similar risks for a woman but without any qualification or classification at all.

Thus, we can conclude that qualification of the software as a medical device is challenging, but the next step with classification is difficult and not clear as well. Despite the existing Manual with examples and explanations, there is a lot of stand-alone software with a medical purpose available at the market without necessary control, management, and confirmation of quality and safety for customers. This issue should be considered and resolved to restrict customers from potential harm such software could pose to their life and health.

\section{CONCLUSIONS}

Summarizing the above mentioned, it is feasible to make the following conclusions:

1. Under the new EU rules, stand-alone software could be classified as Class I, Class IIa, IIb, or Class III (previously, most of the stand-alone software was classified as Class I). The same approach of classification works in the USA, when stand-alone software may be classified as Class I (general controls), Class II (special controls in addition to general controls), or Class III (premarket approval). Under the Ukrainian legislation, stand-alone software classified as Class I that is not compliant with EU Directive and USA guidelines and practice.

2. New rules of classification for EU manufacturers mean higher costs for development and additional time for 
the pre-marker stage, taking into account the involvement of notified bodies in the certification process. It could have a negative impact on small companies and startups with limited resources.

3. The analysis of the certified stand-alone software database allowed to create the next inferences:

- the most popular categories among certified standalone software are Heart/Circulatory System, Diabetes, Patient monitoring, and Respiratory system;

- in the analyzed database, there is 213 certified standalone software. However, in the online stores, much more stand-alone software in the categories Medicine and Health and Fitness are available, which means that there is no effective control on producers and sales of stand-alone software with medical purposes from the authorities' perspective;

- the vast majority (about 71\%) of certified stand-alone software is represented in both the AppStore and the Google Play, indicating that there are sufficient staff to develop and maintain multi-platform software (at least for Android and iOS operating systems), which can usually be afforded by medium and large companies that already have a success story on one of the platforms;

- the vast majority (105 against 20) of medical software, which is designed for the EU market, is classified according to CE I class, which has the lowest degree of risk to humans and provides the most painless procedure for conformity assessment, namely self-assessment and completion declaration, therefore, does not require the involvement of a conformity assessment body.

- most of the medical software available to users in the US (105) was entered the market after submitting form $510(\mathrm{k})$

4. The detailed analysis of applying classification rules to stand-alone software in the category Birth control shows that the four different apps with the same functions and that can be used for the same purpose could be classified as Class I, Class IIa, or Class IIb depending on the manufacturer's purpose. There are a lot of available stanalone software in the same category and for a similar purpose and with similar functions, available for end users without any certification

\section{REFERENCES}

1. Nicole Wetsman. When it comes to fitness trackers and health apps, the FDA says you figure it out. URL: https://www.popsci.com/fdaregulations-fitness-trackers-apps/ (reference date 01.02.2021)

2. Carroll N., Travers M., Richardson I." Evaluating multiple perspectives of a connected health ecosystem", 9th International Conference on Health Informatics (HEALTHINF), Rome,2016, 21-23 February.

3. O'Leary P., Carroll N., Clark, P. and Richardson I. "Untangling the complexity of connected health evaluations", IEEE International Conference on Healthcare Informatics2015 (ICHI 2015), Dallas, 21-23 October.

4. Richardson I. "Connected health: people, technology and processes", Lero Technical Report Series Lero-TR-2015-03, University of Limerick.2015.

5. PashkovV., Kotvitska A., Harkusha A. Legal regulation of the production and trade of medical devices and medical equipment in the EU and US: experience for Ukraine. Wiad. Lek. 2017;70 (3 pt 2):614-618.
6. Pashkov V., Harkusha A. Certain aspects on medical devices software law regulation. Wiad. Lek. 2016; 6: 765-767.

7. Pashkov V., Gutorova N., Harkusha A. Medical device software: defining key terms. Wiad. Lek. 2016; 6: 813-817.

8. Hutorova N., PashkovV., Harkusha A. Virtual augmented reality software in medical rehabilitation: key legal issues. Acta Balneologica. 2018; 2 (152): 55-61

9. PashkovV., Harkusha A., Harkusha Ye. Stand-alone software as a medical device: qualification and liability issues, Wiad. Lek. 2020;10:2282-2289.

10. Council Directive 93/42/EEC of 14 June 1993 concerning medical devices. 0J L 169, 12.7.1993. Amended by Directive 2007/47/EC of the European Parliament and of the Council of 5 September 2007.0J L247, 21.9.2007

11. Regulation (Eu) 2017/745 of The European Parliament And Of The Council. URL: https://eur-lex.europa.eu/legal-content/EN/ TXT/?uri=CELEX:02017R0745-20170505 (reference date 01.02.2021)

12. RIVM Letter report 2018-0083 A. van Drongelen et al. Apps under the medical devices legislation. URL: https://www.rivm.nl/bibliotheek/ rapporten/2018-0083.pdf

13. G. Dragotti, E. Marco de Morpurgo, G. Zappaterra. Mobile Health: Radical change in fitness and wellness is on its way in Italy URL: https://www. dlapiper.com/en/italy/insights/publications/2020/07/mobile-healthradical-change-in-fitness-and-wellness/ (reference date 01.02.2021)

14. Policy for Device Software Functions and Mobile Medical Applications. Guidance for Industry and Food and Drug Administration Staff Document issued on September 27, 2019. URL: https://www.fda.gov/ media/80958/download (reference date 01.02.2021).

15. Postanova Kabinetu Ministriv Ukraïni vid 2 zhovtnya 2013 r 753 «Pro zatverdzhennya texnichnogo reglamentu shhodo medichnix virobiv». URL: https://zakon.rada.gov.ua/laws/show/753-2013-\%D0\%BF\#Text (reference date 01.02.2021).

16. Nakaz M0Z Ukraïni vid 22012020 r 142 «Pro zatverdzhennya metodichnix rekomendacij iz zastosuvannya Texnichnogo reglamentu shhodo medichnix virobiv zatverdzhenogo postanovoyu Kabinetu Ministriv Ukraïni vid 02 zhovtnya 2013 roku 753. URL: https://www. apteka.ua/article/531551 (reference date 01.02.2021).

17. FDA/CE certified apps directory. URL: https://apps.healthskouts.com/ (reference date 01.02.2021).

18. GooglePlayStore, category «Health and Fitness». URL: https://play. google.com/store/apps/category/HEALTH_AND_FITNESS (reference date 01.02.2021).

19. AppStore, category «Health and Fitness». URL: https://apps.apple.com/ us/genre/ios-health-fitness/id6013 (reference date 01.02.2021).

20. Microsoft Store, «Medical». URL: https://www.microsoft.com/uk-ua/ store/top-free/apps/pc?category=Medical (reference date 01.02.2021).

21. GooglePlayStore, category «Medical». URL: https://play.google.com/ store/apps/category/MEDICAL (reference date 01.02.2021).

22. US Food and Drug Administration. Premarket Notification 510(k). URL: https://www.fda.gov/medical-devices/premarket-submissions/ premarket-notification-510k (reference date 01.02.2021).

23. Natural Cycles - Birth Control App. URL: https://play.google.com/store/ apps/details?id=com.naturalcycles.cordova\&hl=nl (reference date 01.02.2021).

24. Manual on borderline and classification in the community Regulatory framework for medical devices. Version 1.22 (05-2019). URL: https:// ec.europa.eu/health/sites/health/files/md_topics-interest/docs/md_ borderline_manual_05_2019_en.pdf (reference date 01.02.2021).

25. GooglePlay search results by request "menstrual calendar for women". URL: https://shly.link/Dw2ss (reference date 01.02.2021). 
The article was prepared for the publication under the fundamental theme "National security in the field of public health: legal remedies against threats" that is being researched Academician Stashis Scientific Research Institute for the Study of Crime Problems of the National Academy of Law Sciences of Ukraine (reg. number in Ukrainian Institute of Scientific and Technical Expertise and Information 0120U105608)

\section{ORCID and contributorship:}

Vitalii M. Pashkov: 0000-0001-9489-7768, A,B,E,F

Oleksii S. Soloviov: 0000-0002-6615-4868 $8^{A, B, D, E, F}$

Yevheniia O. Harkusha: 0000-0002-9932-8756 $6^{A, B, D, E, F}$

\section{Conflict of interest:}

The Authors declare no conflict of interest.

\section{CORRESPONDING AUTHOR}

Vitalii M. Pashkov

Pershotravnevy Avenue, 5, 36011, Poltava, Ukraine

tel: +380666931651

e-mail:v.pashkov26.06@ukr.net

Received: 20.10 .2020

Accepted: 11.01.2021

A - Work concept and design, B - Data collection and analysis, C - Responsibility for statistical analysis,

D-Writing the article, $\mathbf{E}$-Critical review, $\mathbf{F}$ - Final approval of the article 